\title{
THE EFFECTIVENESS OF TWO BRUSHING SYSTEMS FOR POST HARVEST DISINFESTATION OF KIWIFRUIT
}

\author{
P.S. STEVENS ${ }^{1}$ and C.E. MCKENNA ${ }^{2}$ \\ ${ }^{1}$ HortResearch, Private Bag 92169, Auckland, New Zealand \\ ${ }^{2}$ HortResearch, 412 No 1 Road, RD2, Te Puke, New Zealand \\ Corresponding author: pstevens@hortresearch.co.nz
}

\begin{abstract}
The presence of some insect and mite species on kiwifruit at harvest can cause quarantine problems in some overseas markets. There is potential to remove these passenger pests using physical handling methods, such as the fruit brushing systems that are currently used in packhouses. The abilities of two types of post harvest brushing systems to remove surface dwelling insects and mites from kiwifruit were compared. Bins of naturally infested fruit were passed through two contrasting post harvest brushing systems and levels of infestations subsequently compared with unbrushed fruit. Both brushing systems removed more than $85 \%$ of Collembola, thrips, mites and small beetles. However, armoured scale insects were not removed, and a relatively low proportion of whirly-gig mite (Anystis baccarum) cocoons was removed. There were no significant differences between the two brushing systems.
\end{abstract}

Keywords: kiwifruit, disinfestation, post harvest brushes, passenger pests.

\section{INTRODUCTION}

Kiwifruit (Actinidia deliciosa (A. Chev.) C.F. Liang et A.R. Ferguson cv. Hayward marketed as Zespri ${ }^{\mathrm{TM}}$ GREEN and A. chinensis Planch cv. Hort16A marketed as Zespri ${ }^{\mathrm{TM}}$ GOLD) is the most significant fruit crop grown in New Zealand in terms of volumes exported and financial returns. In 2005, kiwifruit exports were worth NZ\$720.2M, representing $60 \%$ of New Zealand's fresh fruit exports and $31 \%$ of total horticultural exports (Kerr et al. 2005). New Zealand kiwifruit are currently exported to more than 60 countries around the world. Being a global supplier of kiwifruit brings many challenges, not least of which is the need to ensure that phytosanitary pests are not associated with fresh fruit exports. The New Zealand kiwifruit industry has a range of strategies in place to manage pests, including specific management interventions along various parts of the production system. For example, selected pesticides may be applied in response to pest monitoring results. The pest and disease management system for kiwifruit in New Zealand is known as 'KiwiGreen' and was implemented throughout the industry between 1992 and 1997 initially as a result of changing acceptability of pesticide residues on fruit for some markets (Suckling et al. 2003). 'KiwiGreen' now serves as a framework for an environmental management system that allows full traceability of the product to meet compliance needs.

One of the outcomes of 'KiwiGreen' has been a substantial reduction in the use of broad spectrum insecticides, and the only products permitted for use leading up to harvest are mineral oil (for scale insect control) and Bacillus thuringiensis (for leafroller control) products. This restricted range of insecticides has resulted in an increased number of passenger, non-pest insects and mites on the fruit at harvest. These passenger insects and mites, which include predatory and fungal feeding species, would previously have been killed by the broad-spectrum insecticides that were routinely applied to control armoured scale insects and leafrollers. While these passenger insects and mites are not necessarily pests, their presence on fruit on arrival in export markets can lead to concern, especially if they cannot readily be identified. 
As these passengers are surface dwelling, the potential to remove them using the fruit dry-brushing systems used in packhouses was investigated. Prior to grading in the packhouse, kiwifruit are passed over a brushing system to remove dirt and debris such as leaves and fruit hairs. In general, the brushes are located below the fruit as they pass over rollers, although the brushing systems found in different packhouses do vary slightly. In some packhouses, the system is modified by the addition of long overhead brushes, which rotate in the opposite direction to the rollers carrying the fruit.

It was hypothesised that (1) the post harvest brushing systems used in packhouses could physically remove a substantial proportion of passenger pests prior to fruit being packed and (2) the 'overhead' brushing system would remove greater numbers of passenger pests than the standard brushing system. The aim of this trial was to test these hypotheses.

\section{METHODS}

Three bins (approximately 3000 fruit/bin) of kiwifruit were picked from each of three kiwifruit blocks in Te Puke at harvest on 7 May 1997. Vines in each block were grown on a T-bar support structure. To maximise the number of passenger pests, fruit were picked from the quarter of the canopy nearest to the ground. One of the blocks had been unsprayed for several seasons, and the other two blocks were managed under an organic regime. The bins of fruit were stored at ambient temperature for two days prior to treatment. On 11 May fruit from one bin from each of the three blocks was passed over a set of standard brushes or modified brushes at two commercial packhouses in the Bay of Plenty. Fruit from the remaining bin from each block was not brushed at all.

Ten subsamples of 100 fruit were collected from each bin after treatment and examined under a stereomicroscope for the presence of any insects and mites. All insects and mites found on the fruit were identified and recorded, as well as whirly-gig mite (Anystis baccarum) cocoons. The physical location of whirly-gig mite cocoons was identified as sepal area, side of fruit or stamen area.

The percentage of fruit in each bin infested with passengers, and the numbers of insects found per fruit in each treatment were compared using Analysis of Variance (ANOVA). Least Significant Differences (LSDs) were calculated to separate treatments if the ANOVA showed significant differences $(\mathrm{P}<0.05)$. Percentages were angular transformed before analysis but values shown in tables are untransformed. The analysis was performed using SAS (SAS Institute Inc. 1985). An infestation index was also calculated to provide a single figure to compare the ability of a treatment both to reduce the percentage of infested fruit and to reduce the number of insects per fruit. This index was calculated by multiplying the percentage of fruit infested by the mean number of passengers per fruit.

\section{RESULTS AND DISCUSSION}

The most common insect contaminants recorded on fruit were the cocoons of Anystis baccarum, the whirly-gig mite, with an average of $64 \%$ of unbrushed fruit infested (Table 1). Whirly-gig mites are generalist predators known to feed on a range of mites and aphids (Cuthbertson \& Murchie 2005). Both brushing treatments significantly reduced the percentage of fruit infested with whirly-gig mite cocoons, but the percentage reduction was less than $30 \%$, and almost half the fruit still had at least one cocoon present.

The small beetles Orthoperus sp. (Col: Corylophidae) and Aridius sp. (Col: Latridiidae) were the next most common insects found on untreated fruit, followed by armoured scale insects (Hem: Diaspididae). Members of the Corylophidae and Latridiidae families are known as 'minute fungus beetles' and 'minute scavenger beetles' respectively, because of their feeding habits and size, but neither is considered a pest. Both brushing systems reduced the number of fruit infested with beetles by more than $95 \%$. Passing fruit through the brushes did not result in any reduction in the percentage of fruit infested with armoured scale insects. However, this result was not unexpected given their firm attachment to their host substrate. The percentages of brushed fruit infested with all other types of insects were significantly lower than the unbrushed fruit. There was no difference in the percentage of fruit infested with passengers after passage through the two different brushing systems. 
TABLE 1: Mean percentage ( $\% \pm \mathrm{SE}$ ) of kiwifruit infested with passenger insects and mites for two types of brushing system and unbrushed fruit. Figures in parentheses show the percentage removed in each treatment compared with unbrushed fruit.

\begin{tabular}{lrrr}
\hline & \multicolumn{1}{c}{ Standard brushes } & \multicolumn{1}{c}{ Overhead brushes } & Unbrushed \\
Armoured scale insects & $9.4 \pm 2.1 \mathrm{a}^{1}(20.3 \%)$ & $11.1 \pm 2.6 \mathrm{a}(5.1 \%)$ & $11.8 \pm 2.8 \mathrm{a}$ \\
Collembola & $0.5 \pm 0.2 \mathrm{a}(86.5 \%)$ & $1.2 \pm 0.4 \mathrm{a}(67.6 \%)$ & $3.7 \pm 1.3 \mathrm{~b}$ \\
Thrips & $0.2 \pm 0.1 \mathrm{a}(71.4 \%)$ & $0.3 \pm 0.1 \mathrm{a}(57.1 \%)$ & $0.7 \pm 0.2 \mathrm{~b}$ \\
Whirly-gig mite cocoons & $49.7 \pm 2.9 \mathrm{a}(22.2 \%)$ & $44.6 \pm 2.8 \mathrm{a}(30.2 \%)$ & $63.9 \pm 3.1 \mathrm{~b}$ \\
Oribatid mites & $0.4 \pm 0.2 \mathrm{a}(90.5 \%)$ & $0.5 \pm 0.1 \mathrm{a}(88.1 \%)$ & $4.2 \pm 0.9 \mathrm{~b}$ \\
Other mites & $0.5 \pm 0.2 \mathrm{a}(68.8 \%)$ & $0.4 \pm 0.1 \mathrm{a}(75.0 \%)$ & $1.6 \pm 0.6 \mathrm{~b}$ \\
Aridius sp. & $0.3 \pm 0.1 \mathrm{a}(98.0 \%)$ & $0.4 \pm 0.1 \mathrm{a}(97.4 \%)$ & $15.3 \pm 2.6 \mathrm{~b}$ \\
Orthoperus sp. & $1.2 \pm 0.3 \mathrm{a}(95.7 \%)$ & $1.1 \pm 0.2 \mathrm{a}(96.0 \%)$ & $27.8 \pm 4.7 \mathrm{~b}$ \\
Other pests & $1.9 \pm 0.3 \mathrm{a}(72.5 \%)$ & $1.9 \pm 0.3 \mathrm{a}(72.5 \%)$ & $6.9 \pm 0.9 \mathrm{~b}$ \\
\hline
\end{tabular}

${ }^{1}$ Numbers within a row followed by the same letter are not significantly different $(\mathrm{P}>0.05)$.

The brushing systems also reduced the numbers per fruit of all insects and mites except armoured scale insects (Table 2). In most cases, the numbers of passengers per fruit were reduced by at least $70 \%$. The numbers of whirly-gig mite cocoons per fruit were reduced by $40-50 \%$.

TABLE 2: The mean ( \pm SE) number of different types of passenger insects and mites per fruit for two types of brushing system and unbrushed fruit. Figures in parentheses show the percentage removed in each treatment compared with unbrushed fruit

\begin{tabular}{|c|c|c|c|}
\hline & Standard brushes & Overhead brushes & Unbrushed \\
\hline Armoured scale insects & $\begin{array}{c}0.134 \pm 0.033 \mathrm{a} \\
(43.9 \%)\end{array}$ & $\begin{array}{c}0.196 \pm 00.48 \mathrm{a} \\
(17.9 \%)\end{array}$ & $0.239 \pm 0.066 a$ \\
\hline Collembola & $\begin{array}{c}0.006 \pm 0.003 \mathrm{a} \\
(91.3 \%)\end{array}$ & $\begin{array}{c}0.018 \pm 0.005 \mathrm{a} \\
\quad(73.9 \%)\end{array}$ & $0.069 \pm 0.029 b$ \\
\hline Thrips & $\begin{array}{c}0.001 \pm 0.001 \mathrm{a} \\
(85.7 \%)\end{array}$ & $\begin{array}{l}0.002 \pm 0.001 \mathrm{a} \\
\quad(71.4 \%)\end{array}$ & $0.007 \pm 0.002 b$ \\
\hline Whirly-gig mite cocoons & $\begin{array}{c}1.573 \pm 0.166 \mathrm{a} \\
(40.5 \%)\end{array}$ & $\begin{array}{c}1.289 \pm 0.129 \mathrm{a} \\
(51.2 \%)\end{array}$ & $2.643 \pm 0.300 b$ \\
\hline Oribatid mites & $\begin{array}{c}0.004 \pm 0.002 \mathrm{a} \\
\quad(91.3 \%)\end{array}$ & $\begin{array}{c}0.005 \pm 0.001 \mathrm{a} \\
(89.1 \%)\end{array}$ & $0.046 \pm 0.010 b$ \\
\hline Other mites & $\begin{array}{c}0.005 \pm 0.002 \mathrm{a} \\
\quad(72.2 \%)\end{array}$ & $\begin{array}{c}0.004 \pm 0.001 \mathrm{a} \\
\quad(77.8 \%)\end{array}$ & $0.018 \pm 0.005 b$ \\
\hline Aridius sp. & $\begin{array}{c}0.003 \pm 0.001 \mathrm{a} \\
\quad(98.5 \%)\end{array}$ & $\begin{array}{c}0.004 \pm 0.001 \mathrm{a} \\
\quad(98.0 \%)\end{array}$ & $0.202 \pm 0.033 b$ \\
\hline Orthoperus sp. & $\begin{array}{c}0.012 \pm 0.003 \mathrm{a} \\
\quad(98.3 \%)\end{array}$ & $\begin{array}{c}0.012 \pm 0.002 \mathrm{a} \\
\quad(98.3 \%)\end{array}$ & $0.690 \pm 0.158 b$ \\
\hline Other pests & $\begin{array}{c}0.019 \pm 0.003 \mathrm{a} \\
(73.6 \%)\end{array}$ & $\begin{array}{c}0.019 \pm 0.003 \mathrm{a} \\
(73.6 \%)\end{array}$ & $0.072 \pm 0.010 b$ \\
\hline
\end{tabular}

${ }^{1}$ Numbers within a row followed by the same letter are not significantly different $(\mathrm{P}>0.05)$. 
Passing the fruit over brushes reduced the overall percentage of infested fruit (all categories of passengers) by approximately $30 \%$, but even after brushing, more than $50 \%$ of fruit was contaminated with some kind of passenger (Table 3). Passing the fruit over brushes also reduced the average passenger load per fruit by approximately $50 \%$. The cumulative effect of reducing the percentage of infested fruit and the number of passengers per fruit resulted in a reduction in the infestation index by approximately $70 \%$ in the brushed fruit.

TABLE 3: The mean ( \pm SE) percentage of kiwifruit infested with passengers, the mean number of passengers per fruit, and the mean infestation index $(\%$ fruit infested $\times$ number passengers/fruit) for two types of brushing system and unbrushed fruit. Figures in parentheses show the percentage removed in each treatment compared with unbrushed fruit.

\begin{tabular}{lccc}
\hline Treatment & $\begin{array}{c}\text { Percentage of } \\
\text { fruit infested with } \\
\text { passengers }\end{array}$ & $\begin{array}{c}\text { Mean number of } \\
\text { passengers per fruit }\end{array}$ & $\begin{array}{c}\text { Mean infestation } \\
\text { index }\end{array}$ \\
\hline Standard brushes & $\begin{array}{c}56.5 \pm 2.56 \mathrm{a}^{1} \\
(28.6 \%)\end{array}$ & $\begin{array}{c}1.8 \pm 0.2 \mathrm{a} \\
(53.9 \%)\end{array}$ & $\begin{array}{c}107.8 \pm 11.9 \mathrm{a} \\
(67.9 \%)\end{array}$ \\
Overhead brushes & $\begin{array}{c}54.9 \pm 1.9 \mathrm{a} \\
(30.6 \%)\end{array}$ & $\begin{array}{c}1.6 \pm 0.1 \mathrm{a} \\
(58.9 \%)\end{array}$ & $\begin{array}{c}89.04 \pm 7.9 \mathrm{a} \\
(73.5 \%)\end{array}$ \\
Unbrushed & $79.1 \pm 2.3 \mathrm{~b}$ & $3.9 \pm 0.4 \mathrm{~b}$ & $336.6 \pm 43.8 \mathrm{~b}$
\end{tabular}

${ }^{1}$ Numbers within a column followed by the same letter are not significantly different $(\mathrm{P}>0.05)$.

Brushes removed only a small proportion of whirly-gig mite cocoons and did not remove armoured scale, so the overall percentage removal was re-calculated with these categories of infestation excluded from the analysis. When armoured scale and whirlygig mites were excluded from the analysis, brushes were found to remove more than $85 \%$ of all passengers (Table 4$)$.

TABLE 4: The mean $( \pm \mathrm{SE})$ percentage of kiwifruit infested with passengers (excluding armoured scale and whirly-gig mite cocoons), the mean number of passengers per fruit, and the mean infestation index (\% fruit infested $\times$ number passengers/fruit) for two types of brushing system and unbrushed fruit. Figures in parentheses show the percentage removed in each treatment compared with unbrushed fruit.

\begin{tabular}{lccc}
\hline Treatment & $\begin{array}{c}\text { Percentage of } \\
\text { fruit infested with } \\
\text { passengers }\end{array}$ & $\begin{array}{c}\text { Mean number of } \\
\text { passengers per fruit }\end{array}$ & $\begin{array}{c}\text { Mean infestation } \\
\text { index }\end{array}$ \\
\hline Standard brushes & $\begin{array}{c}5.1 \pm 0.5 \mathrm{a}^{1} \\
(87.7 \%)\end{array}$ & $\begin{array}{c}0.05 \pm 0.01 \mathrm{a} \\
(95.5 \%)\end{array}$ & $\begin{array}{c}0.35 \pm 0.08 \mathrm{a} \\
(99.5 \%)\end{array}$ \\
Overhead brushes & $\begin{array}{c}5.7 \pm 0.5 \mathrm{a} \\
(86.3 \%)\end{array}$ & $\begin{array}{c}0.07 \pm 0.01 \mathrm{a} \\
(93.6 \%)\end{array}$ & $\begin{array}{c}0.47 \pm 0.10 \mathrm{a} \\
(99.3 \%)\end{array}$ \\
Unbrushed & $41.6 \pm 4.0 \mathrm{~b}$ & $1.10 \pm 0.18 \mathrm{~b}$ & $65.14 \pm 15.6 \mathrm{~b}$ \\
\hline
\end{tabular}

${ }^{1}$ Numbers within a column followed by the same letter are not significantly different $(\mathrm{P}>0.05)$. 
The distribution of whirly-gig mite cocoons was used as an indication of the effective removal zone of the brushing treatments, i.e. whether the cocoons were at the sepal end, the side or stamen end of the fruit. A $\chi^{2}$ analysis showed that the ratios of cocoons found at each location on the fruit differed significantly $(\mathrm{P}<0.05)$ between the three treatments. Fruit treated with the overhead brushing system had a lower proportion of whirly-gig mite cocoons on the side of the fruit than fruit from the other treatments (Table 5), suggesting that the addition of overhead brushes enhanced the removal of passengers from the sides of fruit. However, since many passenger pests are found sheltering within the long hairs at the sepal and stamen ends of the fruit, a more effective system would need to be able to remove passengers from these regions.

TABLE 5: The distribution of whirly-gig mite cocoons on kiwifruit for two types of brushing system and unbrushed fruit. Values are mean percentage $(\%) \pm \mathrm{SE}$ of cocoons on each location on fruit.

\begin{tabular}{lrrr}
\hline Treatment & \multicolumn{1}{c}{ Stem } & \multicolumn{1}{c}{ Side } & \multicolumn{1}{c}{ Base } \\
\hline Standard brushes & $13.9 \pm 1.4$ & $12.2 \pm 1.3$ & $73.8 \pm 2.0$ \\
Overhead brushes & $18.3 \pm 2.1$ & $4.7 \pm 0.6$ & $76.9 \pm 2.1$ \\
Unbrushed & $9.6 \pm 0.8$ & $28.8 \pm 2.2$ & $64.8 \pm 2.7$ \\
\hline
\end{tabular}

In conclusion, this research showed that the dry-brushing systems used in kiwifruit packhouses are a very effective means of reducing the number of insects associated with kiwifruit prior to packing. Both of the brushing systems tested effectively removed a high percentage of all passenger insects and mites, with the exception of armoured scale insects and whirly-gig mite cocoons. The overhead brushing system did not remove significantly more passengers from the whole kiwifruit than the standard brushing system, although there was some evidence that the overhead brushes were able to remove more passengers from the sides of the fruit.

The failure of dry brushes to remove armoured scale insects was not unexpected, as research to evaluate the use of high-pressure water jets to remove armoured scale insects from kiwifruit found that water applied at 1000 psi did not dislodge them (Whiting et al. 1998). Given that armoured scale insects are phytosanitary pests in some markets, it is important that effective methods for managing these species are available. However, it is clear from this trial that control of armoured scale is best focused at other points in the production chain, which may be via pre-harvest interventions or by additional post harvest technologies, such as cold storage, that cause mortality.

\section{ACKNOWLEDGEMENTS}

We thank Alister Hawkey and Hugh Moore for the use of their packhouses. We also thank Steve Owen and Brett Hickman for assisting in the harvesting of fruit. Brett Hickman, Usha Rani and Pene Speechlay provided technical assistance. Thanks also to Dr Rich Leschen for beetle identifications. This work was funded by ZESPRI International Limited.

\section{REFERENCES}

Cuthbertson AGS, Murchie AK 2005. Anystis baccarum - an apple orchard assassin. Biologist 52(6): 324-327.

Kerr JP, Hewett EW, Aitken AG 2005. FreshFacts 2005. The Horticulture and Food Research Institute of New Zealand. www.hortresearch.co.nz (accessed 01 April 2007).

Suckling M, McKenna CE, Walker JTS 2003. Integrated Pest Management in New Zealand Horticulture. In: Maredia KM, Dakouo D, Mota-Sanchez D ed. Integrated Pest Management in the Global Arena. CAB International, UK. Pp. 385-396.

Whiting DC, Hoy LE, Connolly PG, McDonald RM 1998. Effects of high-pressure water jets on armoured scale insects and other contaminants of harvested kiwifruit. Proceedings of the 51st New Zealand Plant Protection Conference: 211-215. 